\title{
A REAL - TIME IRRIGATION CONTROL SYSTEM FOR PRECISION AGRICULTURE USING WSN IN INDIAN AGRICULTURAL SECTORS
}

\author{
Prathyusha.K ${ }^{1}$, G. Sowmya Bala ${ }^{2}$, Dr. K. Sreenivasa Ravi ${ }^{3}$ \\ ${ }^{1,2}$ Assistant Professors, Dept. of ECM, KL University, Vaddeswaram, A.P, India, \\ 1prathyushakuncha@gmail.com, ${ }^{2}$ gsbala.3030@kluniversity.in \\ ${ }^{3}$ Professors, Dept. of ECM, KL University, Vaddeswaram, A.P, India, \\ ravi.kavuluri@kluniversity.in
}

\begin{abstract}
Agricultural sector is playing vital role in Indian economy, in which irrigation mechanism is of key concern. Our paper aims to find the exact field condition and to control the wastage of water in the field and to provide exact controlling of field by using the drip irrigation, atomizing the agricultural environment by using the components and building the necessary hardware. For the precisely monitoring and controlling of the agriculture filed, different types of sensors were used. To implement the proposed system ARM LPC2148 Microcontroller is used. The irrigation mechanism is monitored and controlled more efficiently by the proposed system, which is a real time feedback control system. GSM technology is used to inform the end user about the exact field condition. Actually this method of irrigation system has been proposed primarily to save resources, yield of crops and farm profitability.
\end{abstract}

\section{KEYWORDS}

ARM LPC 2148 Microcontroller, GSM, Temperature, Humidity, Soil moisture, Leaf sensor, PH, Level, Phase sensor.

\section{INTRODUCTION}

India is the agriculture based country. Our ancient people completely depended on the agricultural harvesting. Agriculture is a source of livelihood of majority Indians and has great impact on the economy of the country. In dry areas or in case of inadequate rainfall, irrigation becomes difficult. So, it needs to be automated for proper yield and handled remotely for farmer safety. Increasing energy costs and decreasing water supplies point out the need for better water management.

Irrigation management is a complex decision- making process to determine when and how much water to apply to a growing crop to meet specific management objectives. If the farmer is far from the agricultural land he will not be noticed of current conditions. So, efficient water management plays an important role in the irrigated agricultural cropping systems.

A low cost alternative solution for efficient water management currently in use is drip irrigation systems that consist of an automated controller to turn on \& off the control values, which in-turn helps the farmers by managing the water supply to the crop fields and further maintains the moisture levels of soil that helps in better crop production within the short span of time. 
In this paper an efficient solution for maintaining the water supply to the crop fields based on the climate and soil conditions has been proposed. ARM7LPC2148 microcontroller is used for designing the proposed system. GSM based Irrigation Control System is used to facilitate the farmers with knowledge about the environmental conditions through which the uniformity will be maintained. A GPRS featured mobile phone is used for this application which acts as a communication medium between the proposed system and the end user (farmer).

A control system has been proposed, which is nothing but an embedded system, for monitoring and controlling an agricultural motor and other devices locally using built-in input and output peripherals. The user communicates with the centralized unit through SMS services. The centralized unit communicates with the system through SMS services which will be received by the GSM with the help of the SIM card.

The GSM sends this data to ARM micro-controller. ARM micro-controller also continuously receives the data from sensors in some form of codes. After processing, this data is displayed on the LCD. Once the motor is started, a constant monitoring on soil moisture and water level is done $\&$ once the soil moisture is reached to sufficient level the motor is automatically turned off $\&$ a message is send to subscriber that the motor is turned off.

Level sensors (to monitor the soil condition): If it is dry means, this condition is very harmful to plants. So immediately release the water into the soil and make it wet.

Temperature and humidity: Useful in the case of monitoring the weather conditions.

Water level sensor (to monitor the water level): If the subscriber wants to enquire about the water level status at a particular time, he can send a message to the centralized unit. Centralized unit checks the water level and reply the subscriber with the current status [6].

\section{INVESTIGATION}

Here ARM LPC2148 Microcontroller and GSM are used for the automation of drip irrigation and also to monitor the field and gives the accurate results to the end user (farmer). As shown in the below block diagram (i.e. Fig 1) different types of sensors were used. Those sensors will send the input data to the ARM LPC2148 Microcontroller. Here the microcontroller controls the operation through some AT-command those commands were written in the program and are used easily by the end user (farmer) through the mobile phone services (mobile phones are the end application devices, provided with services, that are been operated easily by everyone in today's society). Through those commands the Microcontroller gives the desired output.

\section{METHODOLOGY}

In general, the sensors will give analog output but our processor will accept only the digital data. So we require a converter ADC, by connecting the sensors to the ADC channel pins which are inbuilt to the processor we get the required form of output. The total circuit arrangement is shown in the below figure (i.e. Fig 1). LCD is for the field display purpose. Here we are using total seven sensors to monitor the field condition. Those are Temperature, Humidity, Soil moisture, Leaf sensor, PH sensor, Level sensor, Phase sensor. A particular set of command words are used to operate the corresponding devices connected to the micro-controller, forming $\mathrm{n}$ embedded system. When an active command is set through the controller by the end user the corresponding sensor will get activated and it sends the information it recorded so far which are displayed on the LCD panel of the system fixed in the field and the output readings in short form are send to the mobile phone of the end user (through which the commands are been initiated) in the form of a 
text message. This facilitates the end user to response immediately further to avoid or to provide the proper supply of water for crop irrigation.

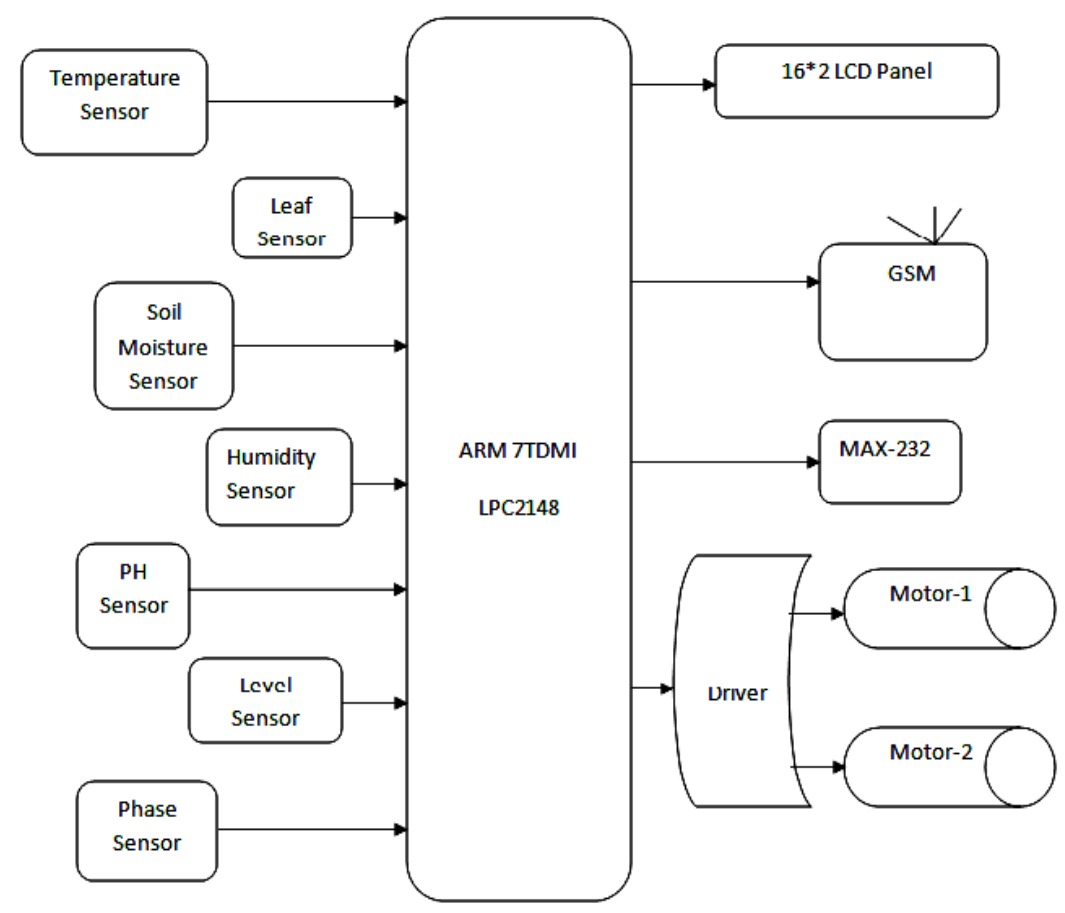

Figure 1: Block Diagram of Real - Time Irrigation System

Here other important devices are AC motors. For soil module and level sensing applications we are using motors. One motor is used to store water and another is for releasing the stored water into the soil. The circuit arrangement is given below and the detailed pin connections are shown below in the Figure 3. These will monitor the field and gives the accurate results to the user. Here the Leaf sensor, PH, Soil, Level sensors are used to monitor weather leafs are healthy or not.

- The PH sensor is used to monitor the soil condition, weather the soil having harmful acidic nature or normal base nature. If acidic nature is present means we have to dilute the content and neutralize it or we will provide the necessary fertilizer.

- In case of soil moisture, we will check weather soil is dry or wet. If it is dry means, this condition is very harmful to plants. So immediately an SMS will be sending to the farmer to release the water into the soil and make it wet. For this we will use the level sensor and phase sensor will be very useful.

- Temperature and humidity are useful in the case of monitoring the weather conditions.

And we are using the two ac motors, one is for the bringing the water into the storage from ground whereas another one is helpful in case of sending water into field from the storage.

\section{CONCEPT OF REAL - TIME IRRIGATION SYSTEM}

By using the concept of modern irrigation system a farmer can save water up to $50 \%$. This concept depends on two irrigation methods those are: conventional irrigation methods like overhead sprinklers, flood type feeding systems i.e. wet the lower leaves and stem of the plants. 
The area between the crop rows become dry as the large amount of water is consumed by the flood type methods, in which case the farmer depends only on the incidental rainfalls. The crops are been infected by the leaf mold fungi as the soil surface often stays wet and is saturated after irrigation is completed.

Overcoming these drawbacks new techniques are been adopted in the irrigation techniques, through which small amounts of water applies to the parts of root zone of a plant. The plant soil moisture stress is prevented by providing required amount of water resources frequently or often daily by which the moisture condition of the soil will retain well. The diagram below shows the entire concept of the modern irrigation system [9].

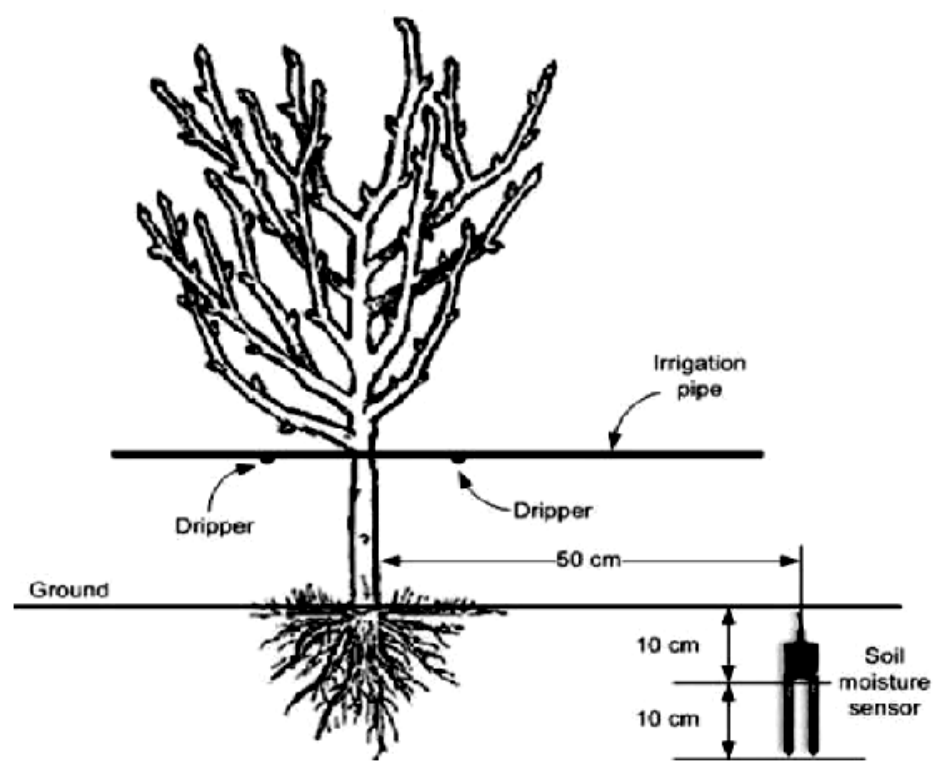

Figure 2: Drip Irrigation [9]

The traditional techniques like sprinkler or surface irrigation requires / uses nearly half of water sources. Even more precise amounts of water can be supplied for plants. As far as the foliage is dry the plant damage due to disease and insects will be reduced, which further reduces the operating cost. The dry rows between plants will leads to continuous federations during the irrigation process.

Fertilizers can be applied through this type of system, and the cost required for will also reduces. The erosion of soil and wind is much reduced by the recent techniques when compared with overhead sprinkler systems. The figure 2 below shows a typical irrigation technique which is applied under a wide range of field conditions [1].

The soil characteristics will define the form of the dripping nature in the root zone of a plant which receives moisture. As the method of dripping will reduce huge water losses it became a popular method by reducing the labor cost and increasing the yields.

\section{CIRCUIT DIAGRAM OF REAL - TIME IRRIGATION SYSTEM}

Our circuit diagram for the real - time irrigation system in agriculture is given below with different types of sensors. The arrangement consists of all the devices and it includes pin connections. Each pin connection is shown clearly in the below figure. All the sensors are connected to the ADC pins. So to convert and use the data, we need to give these outputs to ADC-pins. 


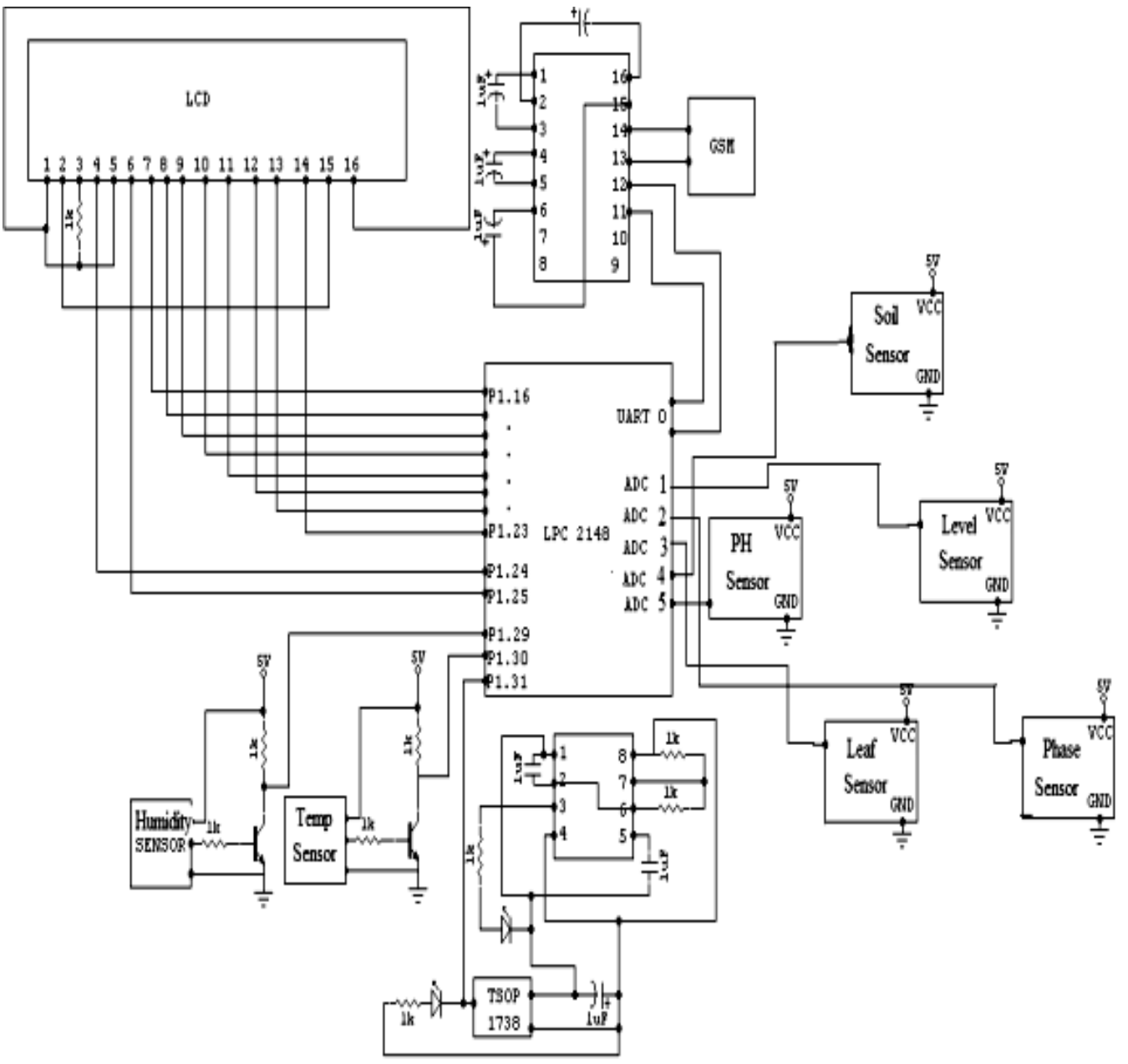

Figure 3: Circuit of real-time automation system

\section{OPERATION OF REAL-TIME ATOMATION OF INDIAN AGRICULTURAL SYSTEM}

Before going to the operation of the circuit, first we have to give the necessary power supply to all the components. The designed components need 5v supply to work whereas the arm processors need 3.3v supply. So we are giving 3.3v from the LM317. This is the device can provide $3.3 \mathrm{v}$ to the processor. For remaining devices will get supply from our power supply circuit will give 5v output. MCU-based home wireless control centre is used along with one WSN centre node module and several data collecting nodes, GSM module, GSM network and mobile phone. The WSN data collecting node modules are connected with different types of sensors.

When the components are activated, all the components will read and gives the output signal to the controller, when the user want to get the information then user should have to send a message from his mobile and immediately corresponding readings will send short message to the users through the GSM module and GSM network immediately. Here we use only GSM for prototype development.

The sensor readings are analog in nature so the ADC pin in the controller will convert the analog signals into digital format. Then the controller will access information. The operation of the circuit is given as, when we want access our field information then we have send a message to GSM modem, that modem consists of SIM (Subscriber Identity Module) and another will be user 
mobile. When user want to access the field information, then user should send message to the GSM.

Then the particular sensor will activate and reads the present condition of the field and gives the same information to the user number. User can analyze the results, if the results are seems to be very bad, then user should provide necessary fertilizers or any other precautions they have to follow.

\section{CONCLUSION}

Real - Time Irrigation Control System for Precision Agriculture using WSN in Indian Agricultural Sectors has been proposed to bring Indian agricultural system to the world class standards. Irrigation in agricultural areas has a crucial importance. With the increasing demand for water resources, optimal usage of water resources has been provided with greater extent by automation technology.

The proposed system is a real time feedback control system which monitors and controls the irrigation system activities efficiently. The results will be displayed on the both LCD panel and user mobile, for testing the output instantly. GSM is responsible for controlling the irrigation on field and sends them to the receiver. The information is send to the user on request in the form of SMS.

\section{FUTURE ENHANCEMENTS}

By developing a Smart Wireless Sensor and by using upcoming techniques a farmer can increase his profit by solving different problems that are faced by the farmer in his routine life. And also to involve ARM - Controller with a video capturing by using an MMS facility about the crop position and at the same time sending video to the farmer.

\section{REFERENCES}

[1] K.Prathyusha, M. Chaitanya Suman, "Design of Embedded System for the Automation of Drip Irrigation”. IJAIEM (2319-4847), vol 1, Issue 2, October 2012.

[2] "Microcontroller based drip irrigation, technical paper on Drip Irrigation”. www.engineers .com April 30, 2010

[3] Chandrika Chanda, Surbhi Agarwal , Er. B.Persis Urbana Ivy, "A Survey of Automated GSM Based Irrigation System”. IJETAE(2250-2459), vol 2, issue 10, October2012

[4] Kshitij Shinghal et. al. "Wireless Sensor Networks Agriculture: For Potato Farming", International Journal of Engineering Science and Technology Vol. 2(8), 2010, 3955-3963

[5] Mahir Dursun, Semih Ozden, "A wireless application of drip irrigation automation supported by soil moisture sensors" Vol 6; 2011 Academic Journals, ISSN 1992-2248, DOI: 10.5897/SRE10.949..

[6] Mr. Srinubabu Aravapalli, Mrs. Ch.Sridevi, Dr. N.S.Murthy Sarma, Mr. K.Raja Sekhar, "Design and Implementation of GSM based Irrigation System Using ARM7”, IJRCCT 2278-5841, Vol 1, Issue 7, December 2012.

[7] LPC-ARM-Book-srn, The Insider's Guide to the PHILIPS ARM\&-Based Microcontroller AT Commands from wave-com.

[8] www. Drip Irrigation Images.com.

[9] http://gardenbot.org/howTo/soilMoisture/. 